\title{
Building Systems and Flexibility: Developing a Conceptual Cost Analysis Framework for Office Buildings
}

\author{
Adel Mohammad A. Binyaseen \\ Department of Islamic Architecture, College of Engineering and Islamic \\ Architecture, Umm Al-Qura University, Makkah, Saudi Arabia \\ binyaseen@yahoo.com
}

(Received: 23/11/2009, Accepted: 15/05/2010)

\begin{abstract}
Flexibility of physical environment in workplaces is an important issue for designers and facility managers in order to understand the implications of any change. This paper develops a conceptual framework for the notion of workplace flexibility. Building systems which represent the physical elements of the workplace are categorized in terms of shell, scenery, services and set. Flexibility is conceptualized in terms of ease to change, and is associated with cost. Most of the research in literature dealt with flexibility in its theoretical concept. This research tried to attach quantitative measures to the concept of flexibility. Three types of change related to cost were developed in association with both performance and time. These are costs of replacement, improvement and movement. The paper claims that through understanding the three types of cost which represent level of flexibility of the physical elements, organizations and designers could select the most appropriate choice of change. Indicators for flexibility and effectiveness were developed. Results of analyzing the three types of change according to the developed framework when applied to air conditioning ducts system in Jaffali office building in Jeddah show variation of flexibility level at different level of change. However, replacement of the whole ducts system are found to be the most expensive choice, whereas improvement of the system is the most effective choice. The paper suggests that such approach could be easily applied to different building systems, as it becomes a helpful tool for designers and managers to resolve the problem of flexibility.
\end{abstract}

Keywords: Flexibility, Building systems, Change, Cost, Office buildings. 


\section{Introduction}

Organizations spend a fortune of their assets in hiring or constructing their own premises. They are always keen to select types of building systems that could be adjusted and changed to cope with future changes. Minor changes often take place in the physical settings of the workplace, which are mainly concerned with partitions and furniture. Major changes are those related to the main building system components such as structural modification, wall subdivisions, and service networking. The new office workplace has been described in terms of built-in flexibility to adapt the changing business requirements ${ }^{[1]}$. However, the importance of flexibility in offices is related to the organization's broad objectives. Flexible business strategies necessitate physical change in a workplace ${ }^{[2]}$. The concept of organic office developed by Ellis has considered both flexibility and management of physical settings as key issues. He defined flexibility of office layouts and partitioning systems as the ability to cope with change ${ }^{[3]}$. The responsible workplace for offices of the future has adopted several design criteria with high emphasis on the need to accommodate greater flexibility in the use of space and time ${ }^{[4]}$.

The one-size-fits-all approaches adopted by many organizations with modular workplaces supported by common areas and privacy spaces to shape their physical layouts have been widely used. Organizations should have more flexibility in shaping their physical settings. As the way people work is changing, the work environment must change to keep pace with the future ${ }^{[5]}$.

Undoubtedly, panel systems have revolutionized workplace layouts. Flexibility of panel systems are the most conceivable by most organizations. Prior to the introduction of panel systems to office layouts, employees remain in open, undivided areas called bull pens. After the emergence of flexible furniture systems, people realized that work and privacy did not have to be mutually exclusive ${ }^{[6]}$.

Davis described the situation of changing the physical layouts in offices of poor level of flexibility as using raised floors for fast-track moving, restructuring universal cabling systems, reconsidering partitions and modular furniture, shrinking spaces, plainer materials, and more power behind walls and beneath floors ${ }^{[7]}$. Future workplaces will provide flexible spaces that comply with jobs, needs, and mood. Technology becomes an integrated part of workplace settings. Office layouts will be 
focused on customization rather than mass appeal. Employees will be able to easily shape their surroundings to suit their work. Furniture and equipment are totally flexible, wireless technology replaces all cables ${ }^{[8]}$. Recent research revealed that new companies' trend in USA use design features that would attract employees to their companies and increase productivity. Flexibility, comfort, security, lighting, and furniture are considered as attracting features ${ }^{[9]}$.

In general, flexibility of physical elements of workplace has been commonly emphasized in order to allow organizations to cope with future change. This paper will focus on the notion of flexibility in office buildings due to increase concern about the importance of the issue of flexibility in future workplaces. Flexibility of building systems will be examined in terms of their ability to change. The paper will introduce a conceptual framework to embody the implications of change in any physical component of offices. The notion of change is adhered to cost; in a way that ease of change is measured in terms of cost. The need for this work is prompted by shortage of practical research in literature which demonstrates the implications of the concept of flexibility with other determinant criteria such as cost, performance, and time quantitatively. Flexibility in literature was often discussed in its theoretical concept, but no practical methods were suggested to measure it. However, this research will give designers and facility managers an insight to understand flexibility in relation to other determinant criteria such as cost, performance, and time in measurable technique, so that they could grasp and manage different parts of building systems according to the rising future change over time.

\section{Building Systems and Flexibility}

Building systems are the final outcome of a series of discussion and analysis between the designer, consultant and the owner. Good choices of building systems reflect the good understanding of organizational requirements over time. The designer's choices of several building systems represent the physical building of organizations. Building systems consist of the basic physical elements. They include constructional elements, services, and other contents. Constructional elements relate to structural parts and dividing walls. Services include all water, gas, electricity and cabling networking. Contents include plants 
and equipment, furnishings, fittings and finishes ${ }^{[10]}$. Building systems were categorized later into four main components. These are Shell, Scenery, Services, and Set. Shell refers to the main structural system of the buildings, it includes columns, slabs, and beams. Scenery refers to internal divisions of walls and partitions. Services refers to all electromechanical systems in buildings including all plumbing system, power systems, IT networks, HVAC systems, elevators, fire systems, alarm systems, etc. Set includes furniture, equipments, accessories and finishes ${ }^{[11]}$.

The level of flexibility of building systems is the result of the designer's decision in selecting that particular element, which is mainly affected by client's desire and needs, allowable budget, and other environmental considerations. Flexibility of any physical element of a building refers to its ability to change. Ease of change will reflect its level of flexibility. In this respect, every physical element could be changed, but is it easy to change it? and how much does it cost? .Answers to these questions will reflect the level of flexibility of the physical element. According to C. Frederick Hess, chairman of International Facility Management Association, if a facility is not designed to be flexible, the potential exists for wasted space and higher costs when changes do take place ${ }^{[2]}$. Thus, low cost change reflects flexible physical elements, whereas high cost change is associated with rigid elements. Physical elements in buildings could have three aspects of change. These are; replacement, improvement and movement. Replacement refers to complete change of the element. Improvement refers to raising the quality of the physical element through extra work or adding extra items. Movement refers to shifting or changing the position of the physical element. In this respect, a single physical building component will have different costs for each type of change depending on ease to accept change.

\section{Research Methodology}

Flexibility in this research is understood as the ability to change as a function of cost required to make the change, though the term "flexibility" implies wider implications such as performing different operation types in different ways, ability to adapt to changes, and the interrelationships between different aspects of flexibility. Building 
systems were analyzed in terms of the three flexibility criteria. These are replacement, improvement, and movement of each building component in order to explore the degree of flexibility of each element. Each type of change has been analyzed in terms of cost. In this respect, three types of cost are emerged. These are; cost of replacement $\mathrm{Cr}$, cost of improvement $\mathrm{Cim}$, and cost of movement $\mathrm{Cm}$. The three types of change were conceptualized in this research as several increments starting from $10 \%$ change to $100 \%$ change, which reflect level of change. This means that any type of change will have a different cost at a different level of change.

Once a certain cost is assigned to a certain type of change at a certain level, designers and facility managers should know how long this change could benefit the organization. Thus, time (T) becomes another factor related to change and cost. The quality of the change is also another important factor. This is related to the performance level of any type of change at different level of different cost. Thus, Performance (P) is another factor, however, performance criteria should be carefully determined. This includes functional, physical, and environmental aspects.

Figure 1 shows the conceptual framework of the flexibility of building systems experiencing three types of change interpreted in terms of cost, time and performance as related factors to the notion of flexibility. The framework will help designers and facility managers to evaluate the level of flexibility of each building component. All types of cost (i.e. cost of replacement $\mathrm{Cr}$, cost of improvement $\mathrm{Cim}$, and cost of movement $\mathrm{Cm}$ ) will vary from 1 -n (i.e. $\left.C_{1}, C_{2}, C_{3}, \ldots, C_{n-1}, C_{n}\right)$. This represents cost increments of change. For example, cost for improving the internal walls Cim varies dramatically depending on the scale of change. As the change becomes greater, the cost will approach the initial cost $C i$ depending on the nature of the physical element. Flexibility Indicators $\mathrm{FI}$ was developed by dividing each type of cost (i.e. $\mathrm{Cr}$, Cim, and $\mathrm{Cm}$ ) on the initial cost $\mathrm{Ci}$. It should be noted that other types of cost such as running cost and operational cost could affect $F I$ in different ways. Thus:

$F I r=C r / C i$ where $F I r$ is Flexibility Indicator for replacement $\mathrm{FIim}=\mathrm{Cim} / \mathrm{Ci}$ where FIim is Flexibility Indicator for improvement $\mathrm{FIm}=\mathrm{Cm} / \mathrm{Ci}$ where $\mathrm{FIm}$ is Flexibility Indicator for replacement 
Where $0 \leq F I \leq 1$ in case of improvement or movement only. FI for replacement could exceeds 1 due to higher $\mathrm{Cr}$ than $\mathrm{Ci}$, resulted from extra cost for removing the physical element and install a new element. As FI approaches 0, it means that the physical element of the building is very flexible, and as it approaches 1 , it means it is a rigid element and it possesses no flexibility at all since any change in this particular element will be equivalent to almost the initial cost $C i$. FI will assist designers to grasp the magnitude of change and the needed cost. All types of cost should be estimated properly so that facility managers will have a clear idea about the implications of any change.

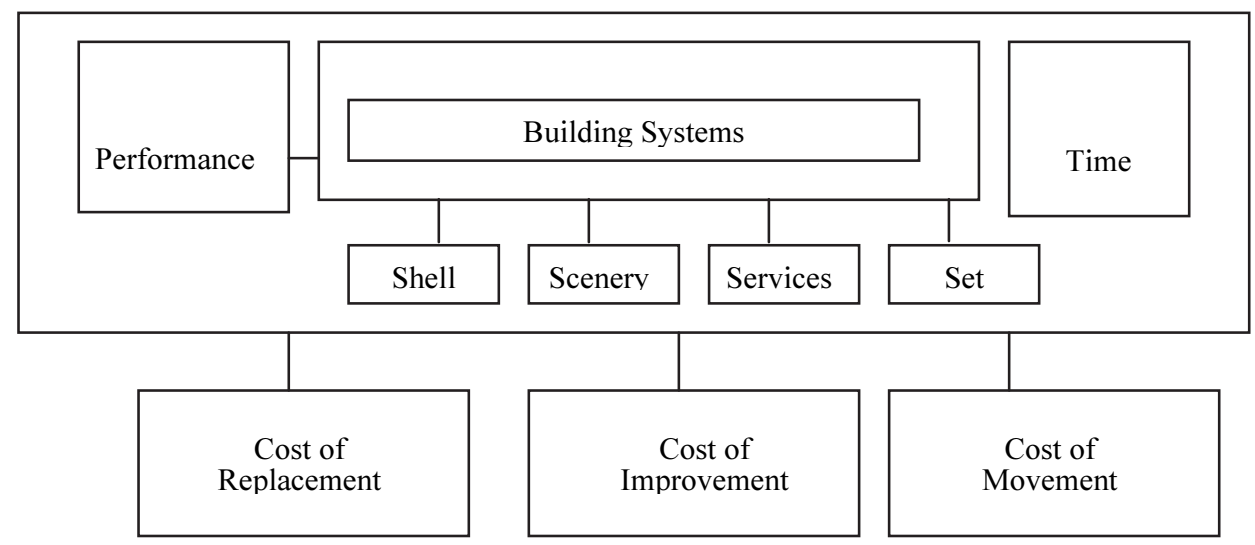

Fig. 1. Conceptual framework of building systems and the three types of change related to cost.

Both Performance $(\mathrm{P})$ of the physical elements after the change as well as the benefited time (T) should be carefully assessed by facility managers. This demands designers to evaluate the level of performance and benefited time at different cost increments $(1,2,3, \ldots, n-1, n)$. For example, if there are ten cost increments to improve a certain physical element in the building, what are the levels of both performance and benefited time associated with each cost increment? Designers could use a scale between $1-12$, where 1 is very poor performance and 12 is very high performance. Benefited time by years should be also carefully estimated based on experience and technical specifications.

Flexibility Effectiveness Feff is a measure developed to assess the value of change at different cost increments. This is mainly related to cost, performance (P), and benefited time (T). Feff is expressed in terms of cost per both time and performance units. Such a relationship is interrelated and will be investigated through statistical analysis. 


\section{Research Case Study}

The developed framework will be applied to Jaffali private office building in Jeddah, which has been constructed approximately 25 years ago. The paper will apply the framework concept on the air conditioning ducts, since it is easier to understand, which includes wiring, dampers, diffusers, accessories, insulations, suspensions, and main duct channels. A.C. professionals participated in evaluating cost, performance and time criteria. The field study conducted in summer 2008 and lasted for three months. It should be noted that similar approach could be applied to any building system components. The three types of cost will be considered in this case study.

\subsection{Replacement Cost}

Replacement cost $\mathrm{Cr}$ for air conditioning ducts system for different cost increments (1-n) was estimated by A.C. professionals. Increments of change were taken at 10 intervals of $10 \%$ each. Table 1 shows the replacement cost $\mathrm{Cr}$ at ten increments of change for air conditioning ducts including wiring, dampers, diffusers, other accessories, insulation, suspension items, and duct channels. Benefited time (T) as well as performance $(\mathrm{P})$ for each increment of replacement were estimated by A.C. professionals. Performance criteria $(\mathrm{P})$ is based on functional and thermal performance. Flexibility Indicators $\mathrm{FI}(\mathrm{Cr} / \mathrm{Ci})$, shows that in all ten increments of change it is greater than 1, which means that air conditioning ducts system in this building is not easy to replace since it requires other additional work and could lead to replacement or fixing other unrelated items which push $\mathrm{Cr}$ value higher than $\mathrm{Ci}$. FI at the first increment R1 closer to 1 (1.04) which means that $\mathrm{Cr}$ is almost equal to $\mathrm{Ci}$, whereas at the last increment $\mathrm{R} 10, \mathrm{Cr}$ will cost $45 \%$ higher than $\mathrm{Ci}$. Thus, replacing any physical element could be described as flexible if its $F I$ is closer to 1 , where $\mathrm{Cr}$ is almost equivalent to $\mathrm{Ci}$. This means that uninstalling an old item in order to install a new item is so easy in a way that it is fast, easy and does not require additional work. Thus, replacement of the duct systems in this building is flexible at a lower level of replacement and tends to get less flexible as the level of replacement increases.

Results of regression analysis in order to obtain the overall relationship between incorporated variables revealed the following equations: 


$$
\begin{aligned}
& C r=27.32+19.69 \mathrm{~T}+15.97 \mathrm{P} \\
& \mathrm{P}=-0.85+0.654 \mathrm{~T} \\
& C r=13.75+30.36 \mathrm{~T}
\end{aligned}
$$

Thus $\mathrm{Cr}$ value for any $\mathrm{T}$ intervals is:

$\mathrm{T} 2$

${ }_{\mathrm{T} 1} \int(13.75+30.36 \mathrm{~T}) d(t)$

The Flexibility Effectiveness Feff is the result of the cost spent in terms of performance and time. Thus:

$$
\begin{aligned}
& F \text { eff }=C r /\left(\mathrm{P}^{*} \mathrm{~T}\right) \\
& F \text { eff }=(13.75+30.36 \mathrm{~T}) /(-0.85+0.654 \mathrm{~T}) \mathrm{T}
\end{aligned}
$$

\begin{tabular}{|c|c|c|c|c|c|c|}
\hline \multirow{2}{*}{$\begin{array}{l}\text { Change increments } \\
1-n\end{array}$} & \multirow{2}{*}{$\mathrm{Ci}$} & \multicolumn{4}{|c|}{ Replacement } & \\
\hline & & $\mathrm{Cr}$ & $\mathrm{T}$ & $\mathrm{P}$ & $\begin{array}{l}\mathrm{FI}= \\
\mathrm{Cr} / \mathrm{Ci}\end{array}$ & Feff \\
\hline $10 \%$ replacement $\mathrm{R} 1$ & 82.350 & 85.650 & 2 & 1 & 1.04 & 81.30 \\
\hline $20 \%$ replacement $\mathrm{R} 2$ & 95.500 & 101.790 & 3 & 1 & 1.07 & 31.42 \\
\hline $30 \%$ replacement $\mathrm{R} 3$ & 126.750 & 140.887 & 4 & 2 & 1.11 & 19.14 \\
\hline $40 \%$ replacement R4 & 170.650 & 195.500 & 6 & 3 & 1.15 & 10.62 \\
\hline $50 \%$ replacement $\mathrm{R} 5$ & 198.300 & 240.560 & 8 & 4 & 1.21 & 7.32 \\
\hline $60 \%$ replacement $\mathrm{R} 6$ & 255.600 & 350.600 & 12 & 6 & 1.37 & 4.50 \\
\hline $70 \%$ replacement $\mathrm{R} 7$ & 295.000 & 402.450 & 13 & 7 & 1.36 & 3.93 \\
\hline $80 \%$ replacement $\mathrm{R} 8$ & 345.550 & 480.500 & 15 & 10 & 1.39 & 3.50 \\
\hline $90 \%$ replacement $\mathrm{R} 9$ & 375.550 & 530.200 & 17 & 11 & 1.41 & 3.04 \\
\hline $100 \%$ replacement $\mathrm{R} 10$ & 430.500 & 622.235 & 20 & 12 & 1.45 & 2.54 \\
\hline
\end{tabular}

Table 1. Replacement as change in terms of cost at ten increments for air conditioning duct system includes wiring ,dampers, diffusers, other accessories, insulation, suspensions, and duct channels.

$\mathrm{C} i=$ Initial Cost in thousands SAR

$\mathrm{T}=$ Benefited Time

$F I=$ Flexibility Indicator

$\mathrm{Cr}=$ Replacement Cost in thousands SAR $\mathrm{P}=$ Performance

Feff=Flexibility Effectiveness

Table 1 shows Feff for the ten increments of replacement cost $\mathrm{Cr}$. Feff at R1 is 81.30 which reflects $C r$ per time and performance units. Feff gets lower as the level of replacement increases, where it reaches 2.54 at R10 Fig. 2. Such results confirm that as far as both time and performance are concerned, replacement cost $\mathrm{Cr}$ is more effective at a higher level of replacement, and it becomes more valuable when replacement reaches R10 (i.e. 100\% replacement). This result should not be confused with FI trend which indicates that the replacement of the duct system of this building is flexible at a lower level of replacement (i.e. R1), and is getting less flexible as level of replacement is getting higher (i.e. R10). 


\subsection{Improvement Cost}

Table 2 shows improvement cost $\mathrm{Cim}$ for ten increments of change for air conditioning duct works for the same case study. From regression analysis we obtain:

$$
\begin{aligned}
& \text { Cim }=0.52+5.10 \mathrm{~T}+5.56 \mathrm{P} \\
& \mathrm{P}=-0.57+1.245 \mathrm{~T} \\
& \text { Cim }=-3.65+12.02 \mathrm{~T} \\
& \text { Feff= Cim } / \mathrm{T} * \mathrm{P} \\
& \text { Feff }=(-3.65+12.03 \mathrm{~T}) /(-0.57+1.245 \mathrm{~T})^{*} \mathrm{~T}
\end{aligned}
$$

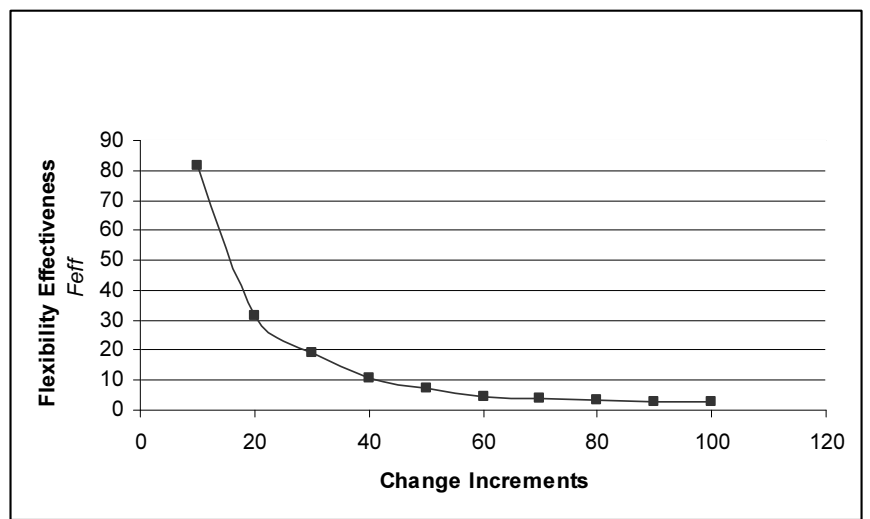

Fig. 2. Relationship between change increments and flexibility effectiveness in replacement change.

Table 2. Improvement as change in terms of cost at ten increments for air conditioning duct system includes wiring, dampers, diffusers, other accessories, insulation, suspensions, and duct channels.

\begin{tabular}{|l|l|l|l|l|l|l|}
\hline \multirow{2}{*}{ Change increments } & \multirow{2}{*}{ 1-n } & \multicolumn{4}{|c|}{ Improvement } & \\
\cline { 3 - 7 } & & Cim & T & P & FI=Cim/Ci & Feff \\
\hline 10\% improvement I1 & 82.350 & 18.500 & 2 & 2 & 0.22 & 5.31 \\
20\% improvement I2 & 95.500 & 29.350 & 2 & 3 & 0.31 & 5.31 \\
30\% improvement I3 & 126.750 & 35.000 & 3 & 3 & 0.27 & 3.41 \\
40\% improvement I4 & 170.650 & 42.300 & 4 & 4 & 0.25 & 2.52 \\
$50 \%$ improvement I5 & 198.300 & 55.100 & 5 & 5 & 0.28 & 2.00 \\
$60 \%$ improvement I6 & 255.600 & 62.500 & 6 & 6 & 0.24 & 1.65 \\
$70 \%$ improvement I7 & 295.000 & 83.000 & 7 & 8 & 0.28 & 1.41 \\
$80 \%$ improvement I8 & 345.550 & 95.200 & 8 & 10 & 0.28 & 1.23 \\
$90 \%$ improvement I9 & 375.550 & 105.000 & 9 & 11 & 0.28 & 1.09 \\
$100 \%$ improvement I10 & 430.500 & 120.500 & 10 & 12 & 0.28 & 0.98 \\
\hline
\end{tabular}

$C i=$ Initial Cost in thousands SAR Cim $=$ Improvement Cost in thousands SAR 
Flexibility Indicator $\mathrm{FI}(\mathrm{Cim} / \mathrm{Ci})$ for improvement cost $\mathrm{Cim}$ shows values between 0.22-0.28 between I1-I10. Although FI shows slight differences between different level of change, it indicates that as level of improvement increases, flexibility level decreases. Flexibility Effectiveness values Feff ranges from 5.31 at I1 to 0.98 at I10. This confirms that making $100 \%$ improvement (i.e. I10) for the air conditioning duct system of this building is more effective once time and performance are involved (Fig. 3).

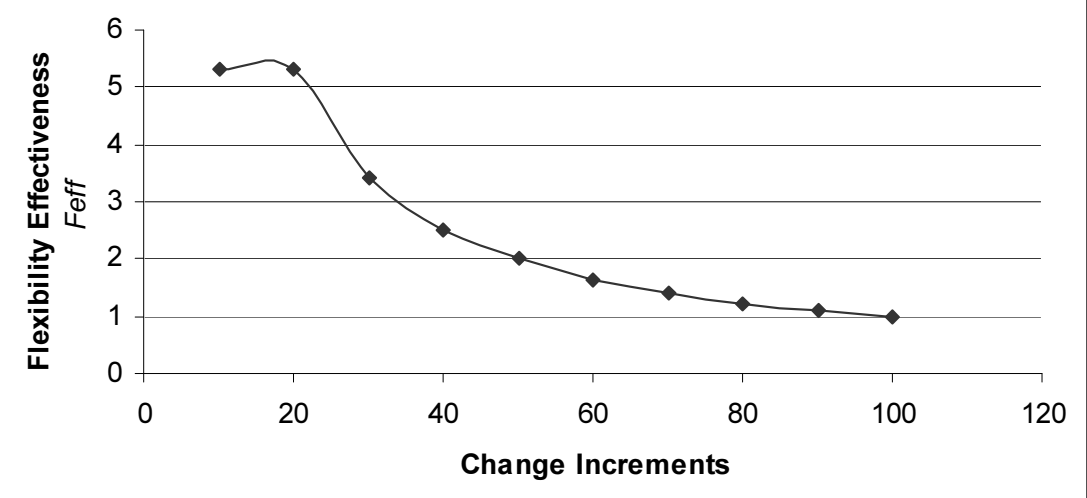

Fig. 3. Relationship between change increments and flexibility effectiveness in improvement change.

\subsection{Movement Cost}

Table 3 shows movement cost $\mathrm{Cm}$ at ten increments M1-M10, since both time $(\mathrm{T})$ and performance $(\mathrm{P})$ are constant here due to using the same parts through the movement process. Performance of air conditioning ducts parts is considered to be at its highest (12/12) over the next 8 years. FI shows an increasing value between $0.18-0.38$ from M1M10 levels of movement, which also means that the duct systems is more flexible at lower level of movement (i.e. M1) and getting less flexible as it approaches higher level of movement (i.e. M10). Feff also shows a risen value between 0.15-1.72 from M1-M10 (Fig. 4), which means that at lower level of movement (i.e. M1), Cm is more effective. 


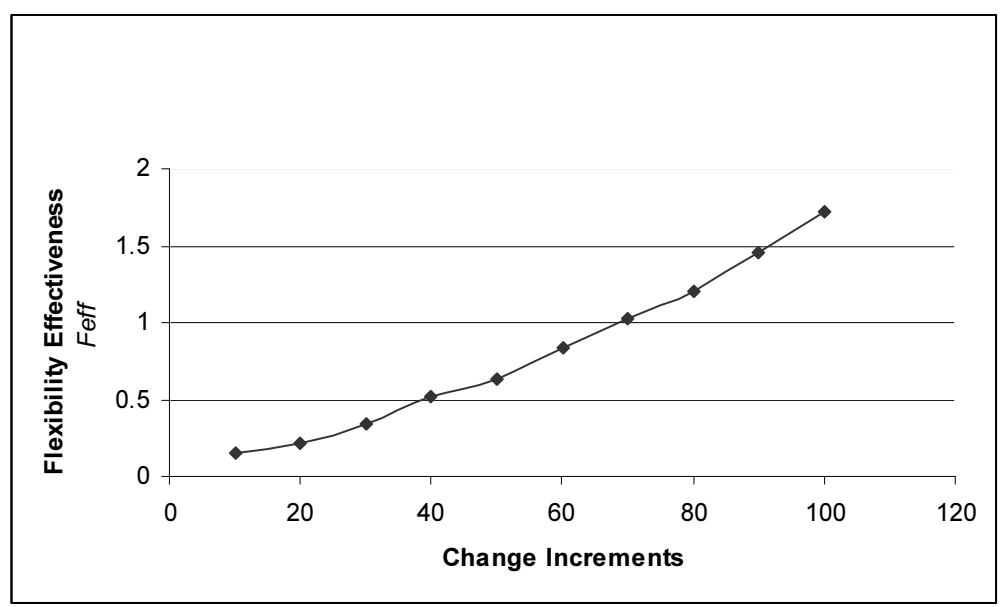

Fig. 4. Relationship between change increments and flexibility effectiveness in movement change.

Table 3. Movement as change in terms of cost at ten increments for air conditioning duct system includes wiring ,dampers, diffusers, other accessories, insulation, suspensions, and duct channels.

\begin{tabular}{|c|c|c|c|c|c|c|}
\hline \multirow{2}{*}{$\begin{array}{c}\text { Change increments } \\
1-n\end{array}$} & \multirow{2}{*}{$\begin{array}{c}\text { Initial Cost } \\
C i\end{array}$} & \multicolumn{4}{|c|}{ Movement } & \multirow[b]{2}{*}{ Feff } \\
\hline & & $\mathrm{Cm}$ & $\mathrm{T}$ & $\mathrm{P}$ & $\mathrm{FI}=\mathrm{Cm} / \mathrm{Ci}$ & \\
\hline $10 \%$ movement M1 & 82.350 & 14.500 & 8 & 12 & 0.18 & 0.15 \\
\hline $20 \%$ movement M2 & 95.500 & 20.750 & 8 & 12 & 0.22 & 0.22 \\
\hline $30 \%$ movement $\mathrm{M} 3$ & 126.750 & 32.600 & 8 & 12 & 0.26 & 0.34 \\
\hline $40 \%$ movement M4 & 170.650 & 49.500 & 8 & 12 & 0.29 & 0.52 \\
\hline $50 \%$ movement M5 & 198.300 & 60.450 & 8 & 12 & 0.30 & 0.63 \\
\hline $60 \%$ movement M6 & 255.600 & 80.350 & 8 & 12 & 0.31 & 0.84 \\
\hline $70 \%$ movement M7 & 295.000 & 98.500 & 8 & 12 & 0.33 & 1.03 \\
\hline $80 \%$ movement M8 & 345.550 & 115.600 & 8 & 12 & 0.33 & 1.20 \\
\hline $90 \%$ movement M9 & 375.550 & 140.000 & 8 & 12 & 0.37 & 1.46 \\
\hline $100 \%$ movement M10 & 430.500 & 165.350 & 8 & 12 & 0.38 & 1.72 \\
\hline
\end{tabular}

$\mathrm{Ci}=$ Initial Cost in thousands SAR

$\mathrm{T}=$ Benefited Time

$F I=$ Flexibility Indicator
$\mathrm{Cm}=$ Movement Cost in thousands SAR $\mathrm{P}=$ Performance

Feff=Flexibility Effectiveness

\section{Conclusion}

This paper is concerned with developing a conceptual framework for evaluating the level of flexibility of building systems. The paper developed a quantitative cost analysis approach with respect to performance and time in order to understand the implication of flexibility of building systems, as this will help designers and facility managers to understand the implications of any change in the physical environment of workplaces. Building systems were categorized in terms of shell, 
scenery, services, and set. Three dimensions of change related to cost were attached to building systems. These were; cost of replacement, cost of improvement, and cost of movement. The three dimensions of change are considered to reflect the level of flexibility of each physical element. Cost was also considered in terms of performance and benefited time.

The paper adopted the air conditioning ducts system in Jaffali main office in Jeddah to apply the conceptual framework. Flexibility indicator as well as flexibility effectiveness for each type of cost were developed. Results revealed clear implications for each type of change on cost in a way that designers and managers could make the most appropriate type of change. Flexibility effectiveness for the three types of change showed that replacement of the air conditioning duct system was the most inefficient type of change; whereas improvement was the most efficient type of change. This paper is an example for how designers and facility managers could take their decision regarding any type of change. Such framework should be tested on other building systems in order to test and compare the applicability of the three types of change.

\section{References}

[1] Rus, M., The New Office, Interior Design, (New York), 72(3) March:125 (2001).

[2] Patterson, M., Reconfiguring the Workplace, Buildings, 90 (March): 40-2 (1996).

[3] Ellis, P., Towards the Organic Office, Facilities, 9(4): 8-12 (1991).

[4] Bre \& DEGW, The Responsible Workplace, A progress Report, AJ, pp: 41-45 (1992).

[5] Babcock, R., The Next Generation, Buildings, 98(4) April: 42-4 (2004).

[6] Budden, C., Putting Panels in Perspective, Buildings, 95(4) April: 28 (2001).

[7] Davis, M., Plugging into the Office of the Future, Public Management, 78 (January): 37 (1996).

[8] Eisenberg, D., What Will Our Offices Look Like? Time, 155(21) may: 82-4(2000).

[9] Tom, K., Trends in Office Design, Interiors \& Sources, 12(2) March: 52-4(2004).

[10] Markus, T. et al., Building Performance, Applied Science Publisher Ltd, London (1972).

[11] Alexander, K., Facility Management Lectures, Center for Facility Management, University of Strathclyde (1992). 


\section{أنظمة المباني والمرونة: تطوير نموذج نظري لتحليل التكلفة

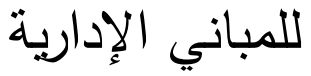

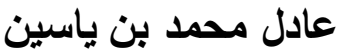

قسم العمارة الإسلامية، كلبة المهنسة والعصارة الإسلامية، جامعة أم القرى، مكة باين

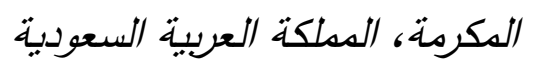

$$
\text { (قدم اللنشر: T/T/T/T) }
$$

المستخلص. تثكل مرونة البيئة المحيطة في أماكن العمل أمرا هاما

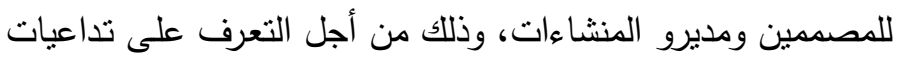

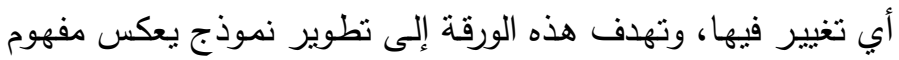

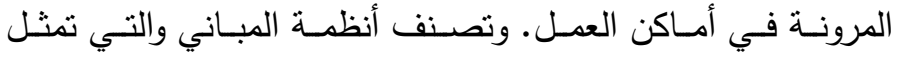

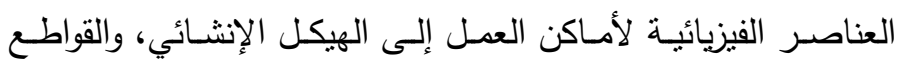
الداخلية، والخدمات، والتجهيزات. وقد نت تبني مفهوم المرونة في هذا لإنا

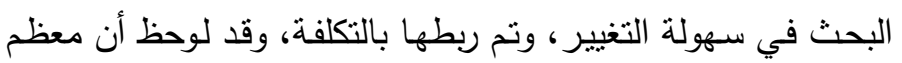

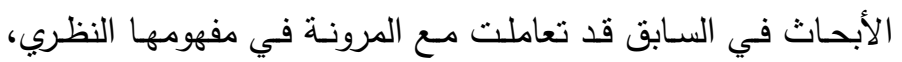
لذلك يهدف هذا البحث إلى تطوير طريقة كمية لمفهوم المرونة. وقد فئد

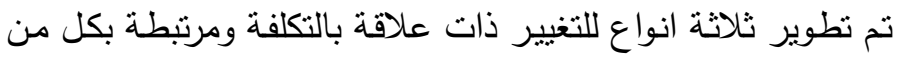

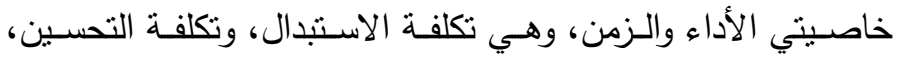

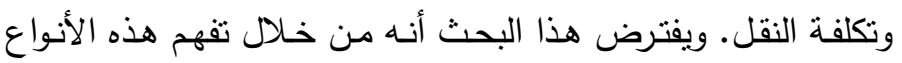

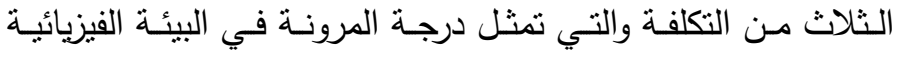
لأماكن العمل، ستمكن المنظمات الإدارية والمصممين من اختيار

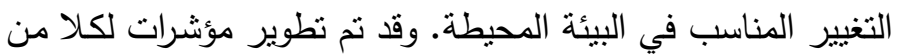
درجة المرونة ودرجة الفعالية، حيث أوضحت النتائج أن هذه الأنواع 
الثلاث من التغيير -حسب النموذج المطور لهذه الورقة- وعندما تم تطبيقه على أنظمة قنوات التكييف في مبـى الجفالي الرئيسي بجدة

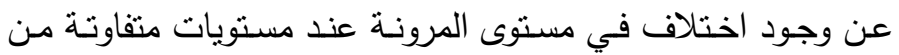

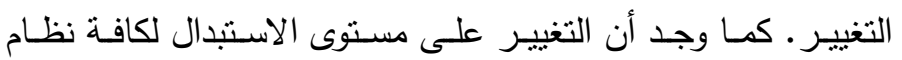
التكييف هو الأكثر تكلفة، بينما التغيير على مستوى التحسين هو

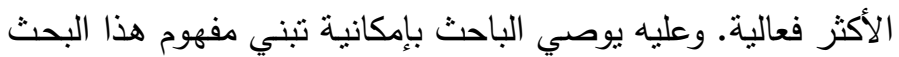

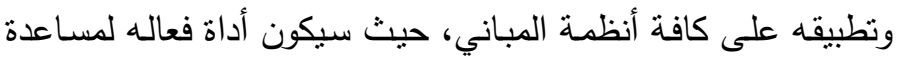
المصممين في حل مشكلة المرونة. الكلمات الدفتاحية: المرونة، أنظمة المباني، التغيير، التكلفة، المباني الإدارية. 